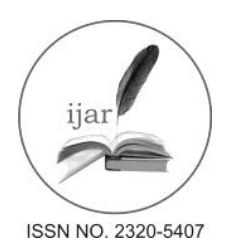

Journal homepage:http://www.journalijar.com

Journal DOI:10.21474/IJAR01

RESEARCH ARTICLE
INTERNATIONAL JOURNAL

OF ADVANCED RESEARCH

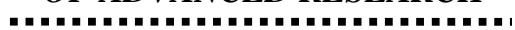

\title{
Lipid peroxidationand antioxidant statusin overt and subclinical hypothyroidism
}

Hamed A. Deraz ${ }^{1}$, *Amira Shoukry ${ }^{1}$, Hoda G. Bakr ${ }^{1}$, Sally M. Shalaby ${ }^{2}$.

1. Internal Medicine Department,Faculty of Medicine, Zagazig University, Zagazig, Egypt.

2. Medical Biochemistry Department, Faculty of Medicine, Zagazig University, Zagazig, Egypt.

\section{Manuscript Info Abstract}

\section{Manuscript History:}

Received: 28 April 2016

Final Accepted: 11 May 2016

Published Online: June 2016

Key words:

Lipid peroxidation; Total

antioxidant capacity; Overt

hypothyroidism; Subclinical

hypothyroidism.

*Corresponding Author

Amira Shoukry.
Background: Oxidative stress, caused by an imbalance in reactive oxygen species produced during normal cell metabolism and/or deficiency of scavenger antioxidant defense, has been implicated in the pathology of several human diseases, including endocrine diseases of thyroid gland.

Aim of the work: The aim of this study is to evaluate the serum levels of malondialdehyde (MDA), a product of lipid peroxidation, and the antioxidant enzymatic activities of superoxide dismutase (SOD) and catalase (CAT) as well as the total antioxidant capacity (TAC) in overt and subclinical hypothyroidism.

Subjects and methods: Forty eight newly diagnosed hypothyroid patients, 24 patients of them have subclinical hypothyroidism (SHT) while the other 24 patients have overt hypothyroidism (OHT), as well as 24 healthy euthyroid control subjects were enrolled in this cross sectional study. Laboratory investigations including lipid profile, thyroid functions as well as levels of serum MDA, SOD, catalase and TAC were estimated.

Results: Both OHT and SHT patients had significantly higher serum TSH, total cholesterol (TC), triglycerides (TGs), LDL-C, catalase, SOD and MDA levels as well as significantly lower serum HDL-C and TAC levels when compared to euthyroid control subjects.

The correlation study revealed that serum TSH levels were significantly positively correlated with TC, LDL-C and TGs serum levels and significantly negatively correlated with HDL-C levels. Moreover, serumMDA, CAT and SOD levels showed significantly positive correlation with TSH, TC, LDL-C and TGs serum levels and a significant negative correlation with free T4, free T3 and HDL-C serum levels.Furthermore, TAC levels showed a significant positive correlation with free $\mathrm{T} 4$, free $\mathrm{T} 3$ and HDL-C serum levels and a negative correlation with TSH, TC, TGs and LDL- C serum levels.

Conclusions: The present study demonstrated that patients with both OHT and SHT showed increased lipid peroxidation and oxidative stress which was evidenced by the increased levels of MDA, a lipid peroxidation product, and the induction of SOD and CAT antioxidantenzymatic activities. Increased MDA and other free radical production could overload the antioxidant system resulting in consumption and severe depletion of antioxidants with concomitant reduction in total antioxidant capacity.

Copy Right, IJAR, 2016, All rights reserved.

\section{Introduction:-}

Hypothyroidism is a clinical entity resulting from the deficiency of thyroid hormones.It is mainly of two types (i) overt hypothyroidism (OHT)which is characterized biochemically by an increase in serum thyroid stimulating hormone (TSH) concentration and a decrease in serumtriiodothyronine(T3) and thyroxine (T4) concentrations below 
normal levels(ii) subclinical hypothyroidism (SHT) whichis a common thyroid disorder characterized by mild elevation in TSH while T3 andT4 are within normal levels [1].

A variety of free radicals such as reactive oxygen species (ROS) are generated during cellular metabolism and their levels are kept in equilibrium with the antioxidant defense systems that scavenge and minimize their formation. Oxidative stress(OXS) is a condition in which the equilibrium between free radical production and their scavenging by antioxidants becomes perturbed favoring increased production of free radicals and/or diminished antioxidants. This leads to accumulation of free radicals or their products within the cells and damage of important biomolecules, such as,DNA, proteins and lipids.OXS has been implicated in the pathology of several human diseases, including endocrine diseases of thyroid gland [2,3]. Thyroid hormones regulate mitochondrial respiration and oxidative metabolism, and thus play an important role in free radical production [4]. In addition, thyroid hormones also regulate the synthesis and degradation of the antioxidant proteins, vitamins and enzymes $[4,5]$.Therefore, variations in the thyroid hormone level may modulate in vivo cellular OXS [6].

Lipid peroxidation is a free radical or ROS-mediated oxidation of cell membrane lipids which results in the formation of toxic and reactive aldehyde metabolites called lipid peroxidation products such as malondialdehyde (MDA) and thiobarbituric acid reactive substances (TBARSs) [7].Free radical-scavenging enzymes, such as superoxide dismutase(SOD) and catalase(CAT), are important intracellular antioxidant enzymes present in aerobic cells and forms the first line of cellular defense against oxidative injury, SOD catalyzes the dismutation of the superoxide anion radicals into hydrogen peroxide $\left(\mathrm{H}_{2} \mathrm{O}_{2}\right)$ which is then deactivated to water $\left(\mathrm{H}_{2} \mathrm{O}\right)$ by catalase or glutathione peroxidase (GPx) [8,9].Serum total antioxidant capacity (TAC) represents a measurement of the combined activities of all antioxidants including enzymatic and non-enzymatic antioxidants in a biological sample and not just the antioxidant capacity of a single compound which may be more informative about the overall antioxidant status [10].

Research interest concerning OXS in hypothyroidism has been in focus in recent years. The available data concerning OXS and antioxidant capacity in hypothyroidism are controversial. Some authors suggested that tissues may be protected from oxidant damage because of the hypometabolic state and the slow rate of free-radical generation caused by the lowered thyroid hormone levels in hypothyroidism [5], whereas; other studiesshowed that oxidative stress was increased in both overt and subclinical hypothyroid disorders [3].

Therefore, the aim of this study was to evaluate the serum levels of malondialdehyde, a product of lipid peroxidation, and the antioxidant enzymatic activities of superoxide dismutase and catalase as well as the total antioxidant capacity in overt and subclinical hypothyroidism.

\section{Subjects and methods:-}

Forty eightnewly diagnosedhypothyroid patients, 24 patients of them have subclinicalhypothyroidism (SHT) while the other 24 patients have overt hypothyroidism (OHT), as well as 24 healthyeuthyroid control subjects were enrolled in this cross sectional study. All patients were recruited from outpatient clinics of Endocrinology Unit of the Internal Medicine Department, Faculty of Medicine, Zagazig University, Egypt between November 2013 and October 2014. All enrolled subjects gave an informed consent for participation in this study and the study protocol was approved by the research ethical committee of Faculty of Medicine, Zagazig University, Egypt.

Hypothyroidism was classified toSHT or OHT according to American Association of Clinical Endocrinologists and The American Thyroid Associationguidelines reported in 2012 (i.e.SHT is diagnosed by a serum TSH above the upper reference limit in combination with a normal free thyroxine (T4), whileOHT is diagnosed by an elevated TSH, usually above $10 \mathrm{mIU} / \mathrm{L}$, in combination with a subnormal free T4) [1].Exclusion criteria to the study were patients taking lipid-lowering drugs, antioxidant vitamin supplements, acetylsalicylic acid, antihistamines, antihypertensives, hormone replacement therapy, smokers, alcoholics, diabetes mellitus, pregnants, and acute, chronic, or malignant diseases.

All enrolled personnel were submitted to history takingincluding past history of thyroid diseases and/or thyroidectomy as well as full clinical assessment including thorough clinical examination and blood pressure measurements. Body mass index(BMI) $\left(\mathrm{kg} / \mathrm{m}^{2}\right)$ was calculated by dividing weight $(\mathrm{kg})$ by height in squared meters $\left(\mathrm{m}^{2}\right)$. Laboratory tests were done in the Medical Biochemistry Department, Zagazig University, Egypt.

\section{Blood sample collection:-}


A 10-mL blood sample was taken from all studied personnel under complete aseptic conditions after 12-14 hours overnight fast. The blood sample was divided into 2 portions: $6 \mathrm{~mL}$ of whole blood was collected in sterile EDTAcontaining tubes for assessment of plasma catalase activity and preparation of erythrocyte lysate for estimation of superoxide dismutase. The other part $(4 \mathrm{~mL})$ was centrifuged at $4000 \mathrm{rpm}$ for 10 minutes and aliquots of serum samples were stored at $-80^{\circ} \mathrm{C}$ until analysis. Serum samples were used for determination of lipid profile, thyroid function tests, MDA and TAC.

\section{Biochemical measurements:-}

Total cholesterol (TC), low density lipoprotein cholesterol (LDL-C), triglycerides (TGs), high density lipoprotein cholesterol (HDL-C), albumin, total bilirubin, alanine aminotransferase (ALT) aspartate aminotransferase (AST),blood urea and serum creatinine were measured by routine enzymatic methods. Fasting blood glucose (FBG) was measured by a glucose oxidase procedure.

\section{Malondialdehyde (MDA) Assay:-}

Measurement of MDA level was done by a commercial chemical colorimetrical assay kit according to manufacturer's protocol (Biodiagnostic, Egypt). MDA in the sample reacts with thiobarbituric acid reagent under acidic conditions at $95^{\circ} \mathrm{C}$ for 30 min to generate a pink colored product determined at $534 \mathrm{~nm}$.

\section{Catalase activity (CAT) assay:-}

CAT activity was measured using a calorimetrically enzymatic assay kit at $510 \mathrm{~nm}$ (Biodiagnostic, Egypt). In this assay, catalase reacts with a known quantity of hydrogen peroxide and the reaction is stopped after 1 min with catalase inhibitor. In the presence of peroxidase, the remaining hydrogen peroxide reacts with 3,5-dichloro-2hydroxybenzene sulfonic acid and 4-aminophenazone to form a chromophore with a color intensity inversely proportional to the amount of catalase in the sample.

\section{Determination of SOD activity:-}

SOD activities were measured according to manufacturer's protocol (Biodiagnostic, Egypt). This assay relies on the ability of the enzyme to inhibit the phenazinemethosulphate-mediated reduction of nitrobluetetrazolium dye. The change of absorbance is measured at $560 \mathrm{~nm}$ calorimetrically.

\section{Total antioxidant capacity (TAC) assay:-}

Serum TAC was measured using a commercial kit following the manufacturer's protocol (Biodiagnostic, Egypt) on the basis of the oxidation reduction colorimetric assay at a wavelength of $532 \mathrm{~nm}$. The method is based on that the antioxidants in the sample eliminate a certain amount of the provided hydrogen peroxide. The remaining $\mathrm{H}_{2} \mathrm{O}_{2}$ is determined colorimetrically by an enzymatic reaction converting 3,5-dichloro-2-hydroxyl benzenesulfonate to a colored product.

\section{Thyroid profile assay:-}

Thyroid profile was assessed by estimation of serum TSH, T3, and fT4 that were measuredby chemiluminescentimmunometric assay by COBAS E 411 Roche Hitashi Apparatus according to manufacturer's protocol (Roche Elecsys reagent kits, Roche Diagnostica, USA). Detection limits for TSH was $0.005-100 \mu I U / \mathrm{mL}$, FT4 was $0.3-100 \mathrm{pmol} / \mathrm{L}$, and T3 was $0.4-50 \mathrm{pmol} / \mathrm{L}$.

\section{Statistical analysis:-}

Continuous variables were checked for normality by using Shapiro-Wilk test. Continuous variables were expressed as the mean $\pm \mathrm{SD}$, and the categorical variables were expressed as a number (percentage). Kruskal-Wallis $\mathrm{H}$ test was used to compare between more than two groups of independent non-normally distributed variables while one way ANOVA test was used for normally distributed variables. Percent of categorical variables were compared using the Chi-square $\left(\chi^{2}\right)$ test. Spearman's rank correlation coefficient was calculated to assess the relationship between various non-normally distributed variables while Pearson's correlation coefficient was calculated for normally distributed variables. All tests were two sided with $\mathrm{p}<0.05$ was considered statistically significant $(\mathrm{S}), \mathrm{p}<0.01$ was considered highly statistically significant (HS), and p> 0.05 was considered non statistically significant (NS). All data were analyzed using SPSS 22.0 for windows (SPSS Inc., Chicago, IL, USA) \&MedCalc 13 for windows (MedCalc Software bvba, Ostend, Belgium). 


\section{Results:-}

The clinical characteristics and biochemical data of patients with SHT and OHT as well as euthyroid control subjects and comparison between the three groups were summarized in Table 1.

There was no significant difference in the mean values of age, male/female ratio, DBP, albumin, total bilirubin, alanine aminotransferase (ALT), aspartate aminotransferase(AST), urea and creatinine among the study groups.

The mean values of SBP, BMI and FBG levels were significantly elevatedin OHT patients compared withSHT patients and euthyroid control subjects.Overt hypothyroid patients had significantly higherserumTSH, total cholesterol, triglycerides, LDL-C, catalase, SOD and MDA levels as well as significantly lower serum free T3, free T4, HDL-C and TAClevels when compared to subclinical hypothyroid patientsand euthyroid control subjects.

Moreover,SHT patients had significantly higherserum TSH, TC, TGs, LDL-C, CAT, SOD and MDA levels as well as significantly lower serum TAC and HDL-C levels when compared to euthyroid control subjects. However, there was no significant difference between both groups in the mean values of serum free T3 and free T4 levels.

Correlations between thyroid hormones, lipid profile and oxidant/antioxidants profile in all studied subjects (N=72) were summarized in Table 2 and 3. The correlation study revealed that serum TSH level was significantly positively correlated with TC (Fig. 1A), LDL-C (Fig. 1B)and TGs serum levels and significantly negatively correlated with HDL-C levels. While, free T3 and free T4 serum levels showed a significant negative correlation with TC, TGs and LDL-C serum levels and a significant positive correlation with HDL-C levels.Moreover, MDA (Fig. 2),catalase and SOD levels showed significantly positive correlation with TSH (Fig. 2A), TC (Fig. 2C), LDL-C (Fig. 2D) and TGs serumlevels and a significant negative correlation with free T4(Fig. 2B), free T3 and HDL-C serum levels.Furthermore, TAC levels showed a significant positive correlation with free T4 (Fig. 3B), free T3 and HDL-C serum levels and a significant negative correlation with TSH (Fig. 3A),TC, TGs and LDL-C serum levels.

Table (1):Demographic,Clinical and biochemical characteristics of the studied groups

\begin{tabular}{|c|c|c|c|c|c|}
\hline Variables & $\begin{array}{c}\text { Euthyroid } \\
\text { Control }(n=24)\end{array}$ & $\begin{array}{c}\text { Subclinical } \\
\text { hypothyroidism } \\
(\mathbf{n}=24)\end{array}$ & $\begin{array}{c}\text { Overt } \\
\text { hypothyroidism } \\
(\mathrm{n}=\mathbf{2 4})\end{array}$ & Test & $\mathbf{P}$ \\
\hline Age (years) & $41.33 \pm 8.10$ & $43.54 \pm 5.05$ & $42.62 \pm 6.51$ & 0.663 & 0.522 \\
\hline Sex & & & & & \\
\hline Male & $7(29.2 \%)$ & $8(33.3 \%)$ & $9(37.5 \%)$ & \multirow[t]{2}{*}{$0.375 \S$} & \multirow[t]{2}{*}{0.829} \\
\hline Female & $17(70.8 \%)$ & $16(66.7 \%)$ & $15(62.5 \%)$ & & \\
\hline BMI $\left(\mathrm{Kg} / \mathrm{m}^{2}\right)$ & $26.54 \pm 2.58$ & $26.75 \pm 2.69$ & $29.50 \pm 3.18^{*} \#$ & $8.143^{\bullet}$ & 0.001 \\
\hline Systolic BP (mmHg) & $110.62 \pm 11.91$ & $116.66 \pm 11^{*}$ & $124.79 \pm 7.86^{* \#}$ & $11.199 \bullet$ & $<0.001$ \\
\hline Diastolic BP (mmHg) & $74.79 \pm 7.29$ & $75.41 \pm 10.20$ & $80.20 \pm 9.38$ & $4.979 \$$ & 0.083 \\
\hline FBG $(\mathrm{mg} / \mathrm{dl})$ & $81.91 \pm 6.31$ & $82.91 \pm 6.27$ & $86.79 \pm 5.51 *$ & $7.442 \ddagger$ & 0.024 \\
\hline Blood urea $(\mathrm{mg} / \mathrm{dl})$ & $30.95 \pm 6.18$ & $29.29 \pm 6.60$ & $27.12 \pm 2.96$ & $2.932 \bullet$ & 0.060 \\
\hline Serum creatinine $(\mathrm{mg} / \mathrm{dl})$ & $0.84 \pm 0.22$ & $0.77 \pm 0.19$ & $0.78 \pm 0.23$ & $1.210 \ddagger$ & 0.546 \\
\hline Serum ALT $(\mathrm{mg} / \mathrm{dl})$ & $24.20 \pm 6.94$ & $20.79 \pm 3.91$ & $20.83 \pm 5.45$ & $3.853 \ddagger$ & 0.146 \\
\hline Serum AST $(\mathrm{mg} / \mathrm{dl})$ & $25.33 \pm 6.43$ & $23.91 \pm 4.33$ & $22.62 \pm 4.48$ & $2.378 \ddagger$ & 0.305 \\
\hline Total bilirubin $(\mathrm{mg} / \mathrm{dl})$ & $0.64 \pm 0.23$ & $0.67 \pm 0.19$ & $0.63 \pm 0.26$ & $0.837 \ddagger$ & 0.658 \\
\hline Albumin $(\mathrm{g} / \mathrm{dl})$ & $4.09 \pm 0.42$ & $4.03 \pm 0.51$ & $3.99 \pm 0.53$ & $1.128 \ddagger$ & 0.569 \\
\hline Total cholesterol $(\mathrm{mg} / \mathrm{dl})$ & $169.73 \pm 11.37$ & $204.75 \pm 14.96^{*}$ & $223.83 \pm 19.46^{* \#}$ & $74.587^{\bullet}$ & $<0.001$ \\
\hline Triglycerides $(\mathrm{mg} / \mathrm{dl})$ & $130.33 \pm 8.65$ & $162.66 \pm 16.24 *$ & $183.16 \pm 15.09^{* \#}$ & $90.172 \bullet$ & $<0.001$ \\
\hline LDL-C $(\mathrm{mg} / \mathrm{dl})$ & $91.00 \quad \pm 13.13$ & $122.91 \pm 16.27 *$ & $142.83 \pm 23.11^{* \#}$ & $50.663 \bullet$ & $<0.001$ \\
\hline HDL-C (mg/dl) & $52.83 \pm 5.29$ & $49.29 \pm 5.55^{*}$ & $43.58 \pm 6.87 * \#$ & $14.770 \bullet$ & $<0.001$ \\
\hline TSH (uIU/ml) & $1.63 \pm 0.63$ & $11.55 \pm 1.01 *$ & $56.40 \pm 6.58 * \#$ & $1368.861 \bullet$ & $<0.001$ \\
\hline Free T3 (pmol/L) & $4.75 \pm 1.11$ & $4.41 \pm 0.79$ & $1.15 \pm 0.46^{* \#}$ & $136.673 \bullet$ & $<0.001$ \\
\hline Free T4 (pmol/L) & $16.79 \pm 2.40$ & $16.17 \pm 2.21$ & $5.70 \pm 1.15 * \#$ & $232.301 \bullet$ & $<0.001$ \\
\hline MDA (nmol/ml) & $0.82 \pm 0.06$ & $2.47 \pm 0.30^{*}$ & $2.89 \pm 0.16^{* \#}$ & $685.379 \bullet$ & $<0.001$ \\
\hline Catalase (U/L) & $12.30 \pm 1.27$ & $15.55 \pm 1.15^{*}$ & $18.35 \pm 2.25 * \#$ & $81.852 \bullet$ & $<0.001$ \\
\hline SOD (U/L) & $8.09 \pm 1.02$ & $9.67 \pm 0.97^{*}$ & $10.69 \pm 1.15^{* \#}$ & $36.879 \bullet$ & $<0.001$ \\
\hline TAC (nmol/ml) & $1.19 \pm 0.19$ & $0.86 \pm 0.19^{*}$ & $0.64 \pm 0.08 * \#$ & $69.124 \bullet$ & $<0.001$ \\
\hline
\end{tabular}

-One Way ANOVA test; $₫$ Kruskal-Wallis H test; $\S$ Chi-square test; $\mathrm{p}<0.05$ is significant.

$* \mathrm{p}<0.05$ compared with the euthyroid control group, and \# $\mathrm{p}<0.05$ compared with thesubclinical hypothyroid group 
BMI: body mass index; BP: blood pressure; FBG: fasting blood glucose; ALT: alanine aminotransferase;AST: aspartate aminotransferase; LDL-C: low density lipoprotein-cholesterol; HDL-C: highdensity lipoprotein-cholesterol;TSH: thyroid stimulating hormone; T3: triiodothyronine; T4: thyroxine;MDA:Malondialdehyde; SOD: Superoxide dismutase; TAC: total antioxidant capacity.

Table (2): Correlation between thyroid function tests, lipid profile andoxidant/antioxidants profile

\begin{tabular}{|c|c|c|c|c|c|c|}
\hline \multirow[t]{2}{*}{ Variables } & \multicolumn{2}{|c|}{ TSH (uIU/ml) } & \multicolumn{2}{|c|}{ Free T3 $(\mathrm{pmol} / \mathrm{L})$} & \multicolumn{2}{|c|}{ Free T4 $(\mathrm{pmol} / \mathrm{L})$} \\
\hline & $\mathbf{r}$ & $\mathbf{p}$ & $\mathbf{r}$ & p & $\mathbf{r}$ & $\mathbf{p}$ \\
\hline Total cholesterol (mg/dl) & +0.950 & $<0.001$ & -0.775 & $<0.001$ & -0.770 & $<0.001$ \\
\hline Triglycerides (mg/dl) & +0.951 & $<0.001$ & -0.796 & $<0.001$ & -0.794 & $<0.001$ \\
\hline LDL-C (mg/dl) & +0.916 & $<0.001$ & -0.760 & $<0.001$ & -0.748 & $<0.001$ \\
\hline HDL-C (mg/dl) & -0.699 & $<0.001$ & +0.674 & $<0.001$ & +0.650 & $<0.001$ \\
\hline Malondialdehyde(nmol/ml) & +0.954 & $<0.001$ & -0.795 & $<0.001$ & -0.783 & $<0.001$ \\
\hline Catalase(U/L) & +0.959 & $<0.001$ & -0.781 & $<0.001$ & -0.778 & $<0.001$ \\
\hline Superoxide dismutase(U/L) & +0.819 & $<0.001$ & -0.683 & $<0.001$ & -0.674 & $<0.001$ \\
\hline TAC $(\mathbf{n m o l} / \mathrm{ml})$ & -0.958 & $<0.001$ & +0.830 & $<0.001$ & +0.846 & $<0.001$ \\
\hline
\end{tabular}

r: correlation coefficient; $\mathrm{p}<0.05$ is significant.

TSH: thyroid stimulating hormone; T3: triiodothyronine; T4: thyroxine; LDL-C: low density lipoprotein-cholesterol; HDL-C: high density lipoprotein-cholesterol;TAC: total antioxidant capacity.

Table (3): Correlation between lipid profile and oxidant/antioxidants profile

\begin{tabular}{|l|c|c|c|c|c|c|c|c|}
\hline \multicolumn{1}{|c|}{ Variables } & \multicolumn{2}{c|}{$\begin{array}{c}\text { Total cholesterol } \\
(\mathbf{m g} / \mathbf{d l})\end{array}$} & \multicolumn{2}{c|}{$\begin{array}{c}\text { Triglycerides } \\
(\mathbf{m g} / \mathbf{d l})\end{array}$} & \multicolumn{2}{c|}{$\begin{array}{c}\text { LDL-C } \\
(\mathbf{m g} / \mathbf{d l})\end{array}$} & \multicolumn{2}{c|}{$\begin{array}{c}\text { HDL-C } \\
(\mathbf{m g} / \mathbf{d l})\end{array}$} \\
\cline { 2 - 9 } & $\mathbf{r}$ & $\mathbf{p}$ & $\mathbf{r}$ & $\mathbf{p}$ & $\mathbf{r}$ & $\mathbf{p}$ & $\mathbf{r}$ & $\mathbf{p}$ \\
\hline Malondialdehyde(nmol/ml) & +0.933 & $<0.001$ & +0.953 & $<0.001$ & +0.905 & $<0.001$ & -0.712 & $<0.001$ \\
\hline Catalase(U/L) & +0.958 & $<0.001$ & +0.957 & $<0.001$ & +0.944 & $<0.001$ & -0.786 & $<0.001$ \\
\hline Superoxide dismutase(U/L) & +0.841 & $<0.001$ & +0.821 & $<0.001$ & +0.838 & $<0.001$ & -0.681 & $<0.001$ \\
\hline TAC(nmol/ml) & -0.963 & $<0.001$ & -0.959 & $<0.001$ & -0.946 & $<0.001$ & +0.764 & $<0.001$ \\
\hline
\end{tabular}

r: correlation coefficient; $\mathrm{p}<0.05$ is significant.

LDL-C: low density lipoprotein-cholesterol; HDL-C: high density lipoprotein-cholesterol;TAC: total antioxidant capacity.

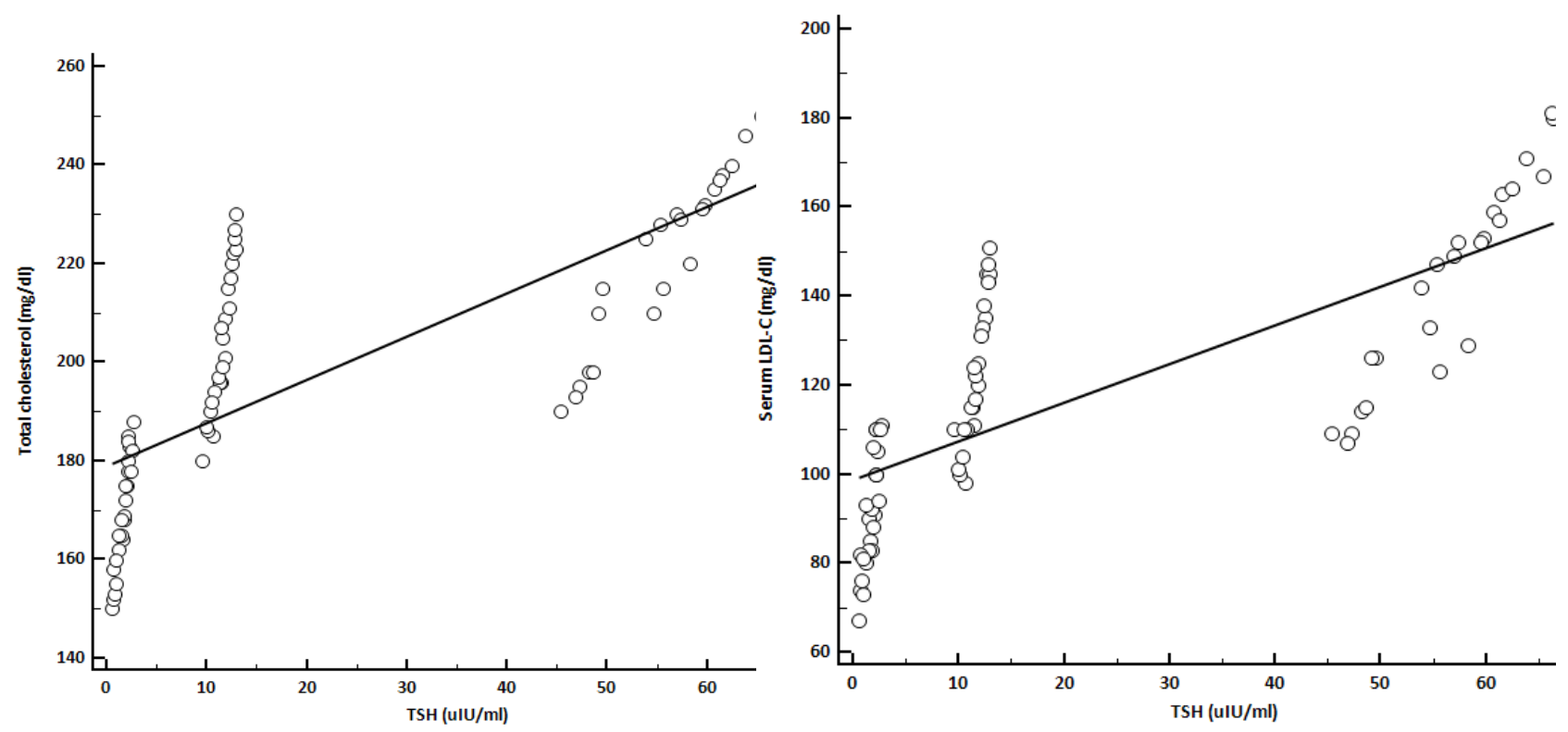

(A)

(B)

Fig. (1): Scatter plot with regression line show correlation between TSH (uIU/ml) and selected study parameters in all studied subjects $(\mathrm{N}=72)$ (A) TSH (uIU/ml)\& total cholesterol (mg/dl); (B) TSH (uIU/ml) \& serum LDL-C $(\mathrm{mg} / \mathrm{dl})$. 

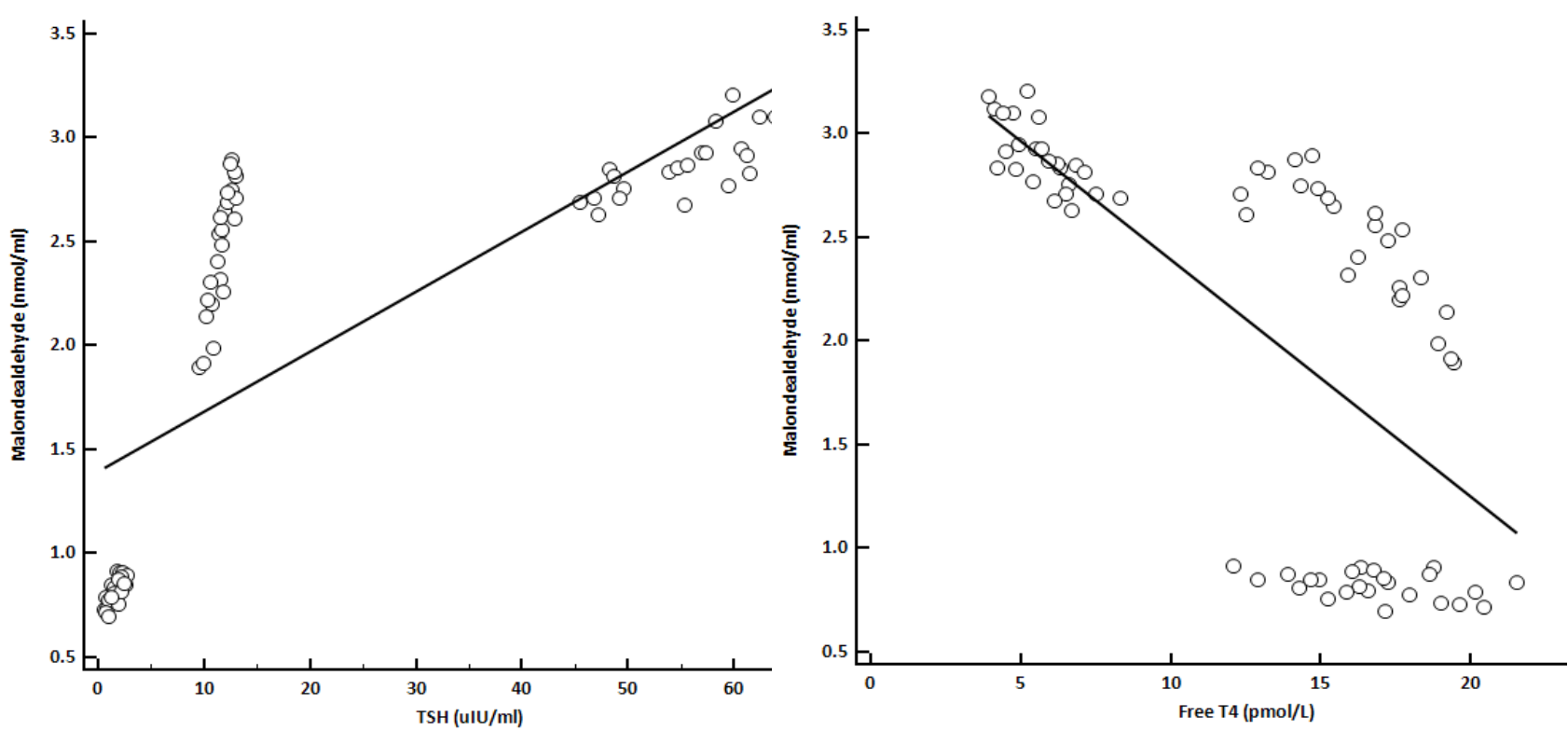

(A)

(B)
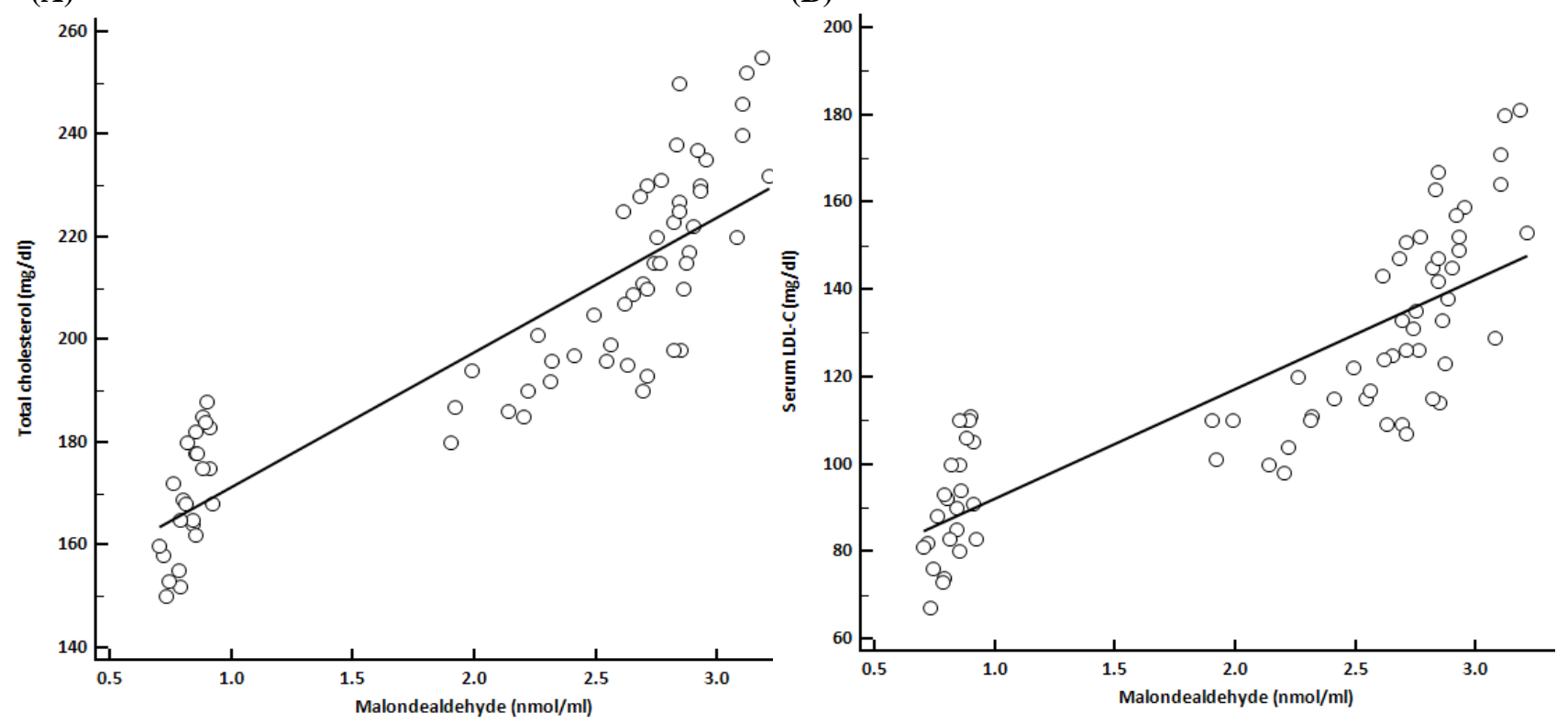

(D)

(C)

Fig. (2): Scatter plot with regression line show correlation between malondialdehyde (nmol/ml) and selected study parameters in all studied subjects (N=72) (A) TSH (uIU/ml)\& malondialdehyde (nmol/ml); (B) Free T4 (pmol/L)\& malondialdehyde $(\mathrm{nmol} / \mathrm{ml})$; (C) Malondialdehyde $(\mathrm{nmol} / \mathrm{ml}) \&$ total cholesterol $(\mathrm{mg} / \mathrm{dl})$; (D) Malondialdehyde $(\mathrm{nmol} / \mathrm{ml})$ \& serum LDL-C $(\mathrm{mg} / \mathrm{dl})$. 


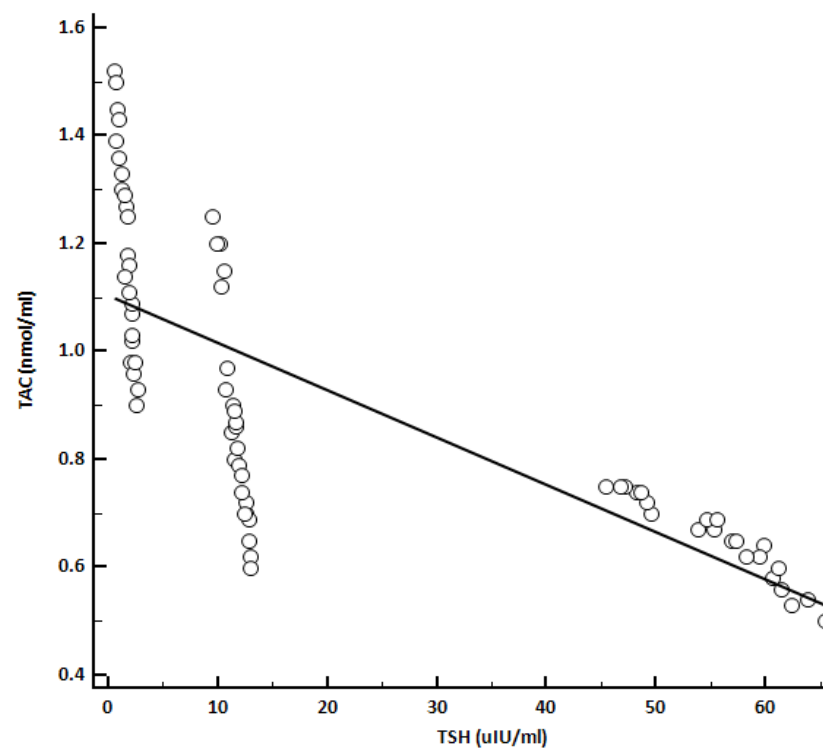

(A)

Fig. (3): Scatter plot with regression line show correlation between TAC (nmol/ml) and selected study parameters in all studied subjects $(\mathrm{N}=72)(\mathrm{A}) \mathrm{TSH}(\mathrm{uIU} / \mathrm{ml}) \& \mathrm{TAC}(\mathrm{nmol} / \mathrm{ml}) ;(\mathrm{B})$ Free T4 (pmol/L) \& TAC (nmol/ml).

\section{Discussion:-}

Oxidative stress, caused by an imbalance in reactive oxygen species (ROS) produced during normal cell metabolism and/or deficiency of scavenger antioxidant defense, has been implicated in the pathology of several human diseases, includingendocrine diseases of thyroid gland[2,3]. The available data concerning OXSand antioxidant capacity in hypothyroidism are controversial. Some authors suggested that tissues may be protected from oxidant damage because of the hypometabolic state in hypothyroidism[5], whereas; other studies found that oxidative stress is increased in both OHT and SHT disorders [3]. Therefore, in this study we aimed to evaluatethe serum levels of MAD and the antioxidant enzymatic activitiesof SOD and CAT as well as the TAC in overt and subclinical hypothyroidism.

The results of the present study revealed that both OHT and SHT had significantly higher serum TC, TGsand LDLClevels as well as significantly lower serumHDL-C levels compared witheuthyroid control subjects.Correlation between thyroid hormones and lipid profilerevealed that serum TSHlevel was significantly positively correlated with TC, TGs and LDL-C serum levels and significantly negatively correlated with HDL-C levels. Furthermore, free T3 and free T4 serum levelsshowed a significant negative correlationwith TC, TGs and LDL-C serum levels and a significant positive correlation with HDL-C levels.In this respect, our results showed that patients with both SHT and OHT had hypercholesterolemia, hypertriglyceridemia, elevated LDL-C and reduced HDL-C levels thus displaying amore atherogenic lipid profile when compared with healthy individuals.

In accordance with our results, several studies have reported increased levels of TC and LDL-C in OHT [11-13]and SHT[14-18].In addition, some studies have shownthat dyslipidemia may also be accompanied by elevated TGs levels in OHT [11-13] as well as in SHT [18, 19]. Data regarding HDL-C are scarce reporting higher HDL-C [11], similar HDL-C [3, 20] or lower HDL-C [19, 21] levels in OHT and SHT compared to euthyroid subjects.Furthermore, some studies demonstrated that serum TSH was positively correlated with TC, TGs, and LDL-C, but no associations were observed between serum TSH and HDL-C [15, 22]. Indeed,even within the normal range of TSH values, a linear increase in total cholesterol, LDL-C and triglycerides and a linear decrease in HDL-C levels have been observed with increasing TSH [23]. However, other studiesshowed no significant differences in serum TC, LDL-C, HDL-C, or TGs levels between SHT patients and the euthyroid controls [22,24,25].

Elevations in total cholesterol and LDL-C may occur in hypothyroidism due to several changes in the synthesis, metabolism, and mobilizationof lipids. Thyroid hormones especially T3 induces 3-hydroxy-3-methylglutarylcoenzymeA(HMG-CoA) reductase which is the first step in cholesterol biosynthesis [26].They also upregulates LDL-C receptors that mediate uptake of cholesterol-rich LDL-C via directly binding to specific thyroid hormone 
responsive elements [27].Therefore, hypercholesterolemia in both OHT and SHT is due to decreased fractional clearance of cholesterol from the plasma and reduced LDL-C uptake by liver and other tissues as a result of reduced number of LDL-C receptors [27].Likewise, hypertriglyceridemia in both OHT and SHT is due to decreased activity of lipoprotein lipase, which is also stimulated by T3 [28]. Lipoprotein lipase lowers TGlevels through hydrolysis of triglycerides in TG-rich lipoproteins(i.e. Verylow density lipoproteins (VLDL) and chylomicrons) into fatty acids and glycerol [17].

Catalase and SOD are important intracellular free radical-scavenging antioxidant enzymes present in aerobic cells, and form the first line of cellular defense against oxidative injury[20, 29].

In the present study, both OHT and SHT patients had significantly higherCAT and SOD levelscompared to the control subjects.In addition,CAT and SOD levels showed significantlypositive correlation with TC, TGs, LDL-C and TSH serum levels and a significant negative correlation with HDL-C, free T3 and free T4 serum levels.Previous studies have reported controversial findingson antioxidant enzymes CAT and SOD in OHT and SHT.In agreement with our findings some studies demonstrated an increase in CATactivityin OHT [20, 30], as well as inSHTpatients [29]. Also, our results were in accordance with several studies which demonstrated a significant increase in SOD activity in OHT patients [20,30,31,32]. In addition, some recent studies showed that CAT levels were correlated with TSH, TC, and LDL-C However, after controlling TC levels, the association between CAT and TSH was not significant suggesting that oxidative stress is likely to be potentially related to the hypercholesterolemia which occur secondary to thyroid dysfunction and not directly to thyroid hormone levels in both OHT [20] and SHT[29].However, there are contrasting reports showing significantly decreased SOD activityin OHT [33,34,35] and in SHT [34] patients, or no change in SOD activityin OHT [4] and in SHT [29] patients. Also, some studies, contradictory toour findings, have demonstratedsignificantly decreased CAT activity in OHT[32,35] or no change in CAT activity in OHT [36] and SHT[34] patients compared to controls.

Lipid peroxidation is caused by ROS-mediated oxidation of cell membrane lipids.Decomposition of peroxidized lipid yields a wide variety of end-products, including malondialdehyde (MDA) and thiobarbituric acid reactive substances (TBARSs)[7].In this study, MDA levels were significantly elevatedin both OHT and SHT patients compared to the control subjects indicating increased lipid peroxidation. Our finding of high MDA level in OHT group compared to SHT group indicate that oxidative damage increases with increased severity of hypothyroidism.Moreover, serum MDA levels showed significantly positive correlation with TC, TGs, LDL and TSH serum levels and a significant negative correlation with HDL, free T3 and free T4 serum levels.Our results areconsistent with several studieswhich demonstrated that MDA levels were significantly elevated in OHT [3, 21, 34, 36 - 39] as well as in SHT[3, 21, 34, 37, 40] patients compared with euthyroid controls which may be an indirect suggestion of increased oxidative stress in these pathological states.In addition, some of the previous studies found a significant correlation between TSH and MDA which was lost after nullifying the effects of each of the coronary lipid risk factors among hypothyroid subjects and suggested that the increase in MDA was not associated with thyroid hormones but was related to elevated plasma lipids [38, 39].

In agreement with our results, some studiesreported increasedconcentrations of TBARSs, another marker of lipid peroxidation, in the circulation of OHT [20] and in SHT[29] patients. Moreover, in the previous studies, TBARSs were correlated with TSH, TC, and LDL-C; however, after controlling TC levels, the association between TSH and TBARSs was not significant suggesting that increased lipid peroxidation could be attributed to lipid levels in hypothyroid status.In contradictory to our results,some studies showed that there is no significant alteration of plasma TBARSs in OHT[41] or SHT patients[41, 42] compared to euthyroid controls. Thus, lipid oxidation in OHT and SHTmay not have beendirectly caused by low thyroid function, but wasenhanced by the presence of elevated plasma cholesteroland LDL-C secondary to hypothyroidism. Prolonged availability of oxidation substrates, mainly LDL-C, in the plasmaincreases their susceptibility to oxidative modification [43]. Oxidized LDL-C impairs endothelial function leadingto atherosclerosis, the first major cardiovasculardisease event. It is plausible that thyroid hormonesimpacted first on lipids causing hyperlipidemia, andexcess lipids acted as substrates for T3. Consequently,accelerated consumption of oxygen by T3 occurred,resulting in enhanced generation of ROS, higher consumptionof cellular antioxidants and inactivation ofantioxidant enzymes [44,45].Aerobic organisms have developed complex antioxidantsystems that can counteract ROS and freeradicals. This system can prevent and/or reduce ROS andfree radical-induced oxidative damage to tissuesand cells and is composed ofdifferent antioxidant substances, including enzymatic, non-enzymaticantioxidants, an array ofsmall molecules and many unknown antioxidant substances $[20,46]$. 
In recent years, interest has grown in studying the roleplayed by oxidative stress in hypothyroidism byinvestigating one or more of the antioxidant markers including SOD, CAT [4,20,29,34,35],GPx, glutathione-S-transferase (GST), glutathione [34,35], vitamin A ( $\beta$-carotene), vitamin $\mathrm{E}$ (a- tocopherol), Vitamin $\mathrm{C}$ (ascorbic acid)[4,35].However, the measurement of different antioxidant molecules separately was not only impracticaland timeconsuming but also held no clinical significance because the effects of antioxidants can be additive,moreover, the dynamic distribution of different antioxidants in various biological samples and their potential interactions make it difficult to measure each antioxidant separately, and such measurements are also unlikely to represent the overall antioxidantsubstances in the body.Therefore, it is essential to measure the levels of overall antioxidants, including those known and unknown antioxidants to assess the antioxidant status in vivo [46].

In the present study, we measured serum total antioxidant capacity (TAC) that represents a measurement of the combined activities of all antioxidants including enzymatic and non-enzymatic antioxidants in a biological sample and not just the antioxidant capacity of a single compound, which may be more informative about the overall antioxidant status[10]. In the present study, both OHT and SHT patients had significantly lower serum TAC levels compared to the control subjects.TAC levelsshowed a significant positive correlation with HDL, free T3 and free T4 serum levelsand a negative correlation with TC, TGs and LDL and TSH serum levels.In consistence with our results,some studies found that TAC was decreased in OHT as well as SHT patients compared to control[3,21].Our findingsare -however- contradictory to a previous study that demonstrated no changes in TAC in SHTpatients when compared to euthyroid control [40].

Although the pathophysiological consequences of the decreased levels of antioxidant capacity are not yet elucidated, this biochemical change is thought to be a physiological adaptation and response to hypothyroidism. Thyroid hormones are involved incombating against the toxicity of oxidative stress in animals and in human as theyregulate the synthesis and degradation of the antioxidant proteins, vitamins and enzymes [5, 35].Another explanation for decreased TAC in OHT and SHT is the persistent hypercholesterolemia thatenhances lipid peroxidation with increased MDA and other free radical production; this could overload the antioxidant system resulting in consumption and severe depletion of antioxidants with concomitant reduction in total antioxidant capacity [40].

In this study, oxidative stress was found to be increased in both overt and subclinical hypothyroid patients as indicatedby the elevated lipid peroxidation product, malondialdehyde and the oxidant imbalance due to LDL-C oxidation caused the cells to respond by increasing antioxidant enzymes SOD and catalase activities to counter ROS generation. The mechanism of increased OXS in hypothyroidism is likely to be multifactorial. It was described that, despite being a hypometabolic state, increased lipid peroxide levels can occur in hypothyroidism due to slower clearance rate [38]. Hyperlipidemia, decreased cholesterol clearance, deficient antioxidant system, effects of thyroid hormones on regulation of antioxidant enzymes and excess TSH are the other proposed mechanisms associated with increased OXS in hypothyroidism [37].

In overt hypothyroidism, administration of substitution therapy with L-thyroxine is usually needed to correct dyslipidemia[27]. In addition, some studies demonstrated that after achievingeuthyroid state there was a significant decrease in MDA levels and improvement of oxidative stress in the patients with hypothyroidism[4, 39]. Also, hypercholesterolemic patients with SHT especially thosewith prominent thyroid dysfunction(TSH levels >10 $\mathrm{mIU} / \mathrm{L}$ ), may betreated with thyroxin substitution therapy, since the restorationof euthyroidism can effectively improve lipid levels, relieve certain symptoms, and may also prevent progressionto overt hypothyroidism [27].

\section{Conclusion:-}

The present study demonstrated that patients with both OHT and SHT showedan increasedlipid peroxidation and oxidative stress which was evidenced by the increased levels of MDA, a lipid peroxidation product, and the induction of SOD and catalase antioxidant enzymatic activities. Increased MDA and other free radical production could overload the antioxidant system resulting in consumption and severe depletion of antioxidants with concomitant reduction in the total antioxidant capacity.

\section{Recommendations:-}

We suggest that monitoring of thyroid hormones and lipids should be considered in the management of hypothyroidism to determine the appropriate dosage of L-thyroxine substitution therapy. Also, lipid lowering drugs 
may be useful in the reduction of oxidative stress in hypothyroidism. In addition to routine monitoring of hypothyroid patients for their TSH levels, measurement of MDA and TAC might be considered for evaluation of oxidative injury.Hypercholesterolemic patients with SHT, especially those with prominent thyroid dysfunction (TSH levels $>10 \mathrm{mIU} / \mathrm{L}$ ), may be treated with thyroxin substitution therapy and/ or lipid lowering drugs, since the restoration of euthyroidism can effectively improve lipid levels and reduce oxidative stress. Furthermore, supplementation of antioxidants (antioxidant vitamins, copper, and zinc) in doses sufficient to combat oxidative stress may be a useful adjunct and should be considered in the management of hypothyroid patients.Further larger clinical studies are required to better understand the role of oxidative stress on the physiopathology of hypothyroidism.

\section{References:-}

1. American Association of Clinical Endocrinologists and American Thyroid Association : Garber JR, Cobin RH, Gharib H, Hennessey JV, Klein I, Mechanick JI, Pessah-Pollack R, Singer PA, Woeber KA; Clinical practice guidelines for hypothyroidism in adults. Endocr Pract 2012;18(6):988-1028.

2. Valko M, Leibfritz D, Moncol J, Cronin MT, Mazur M, Telser J. Free radicals and antioxidants in normal physiological functions and human disease. Int J Biochem. Cell Biol2007; 39: 44-84.

3. Torun A N, Kulaksizoglu S, Kulaksizoglu M, Pamuk B O, Isbilen E, Tutuncu N B. Serum total antioxidant status and lipid peroxidation markermalondialdehyde levels in overt and subclinical hypothyroidism. ClinEndocrinol $2009 ; 70: 469-$ 474.

4. Erdamar H, Demirci H, Yaman H, Erbil M K , Yakar T, Sancak B, Elbeg S ,Biberoğlu G, Yetkin I. The effect of hypothyroidism, hyperthyroidism, and their treatment on parameters of oxidative stress and antioxidant status. ClinChem Lab Med $2008 ; 46: 1004-1010$.

5. Pereira B , Rosa L F, Safi D A, Bechara E J, Curi R . Control of superoxide dismutase, catalase and glutathione peroxidase activities in rat lymphoid organs by thyroid hormones. J Endocrinol $1994 ; 140: 73-77$.

6. Guerrero A, Pamplona R, Portero-Otin M , Barja G, Lopez-Torres M . Effect of thyroid status on lipid composition and peroxidation in the mouse liver. Free RadicBiol Med 1999; $26: 73-80$

7. Halliwell B , Chirico S. Lipid peroxidation: its mechanism, measurement and significance . Am J ClinNutr 1993;57: 715 724.

8. Fridovich I. Superoxide radical and superoxide dismutase. Ann Rev Biochem $1995 ; 64: 97-112$.

9. Sies H. Strategies of antioxidant defence . Eur J Biochem 1993;215: 213 - 219.

10. Erel O. A novel automated direct measurement method for total antioxidant capacity using a new generation, more stable ABTS radical cation. ClinBiochem 2004; 37: 277-285.

11. Pearce EN, Wilson PW, Yang Q, Vasan RS, Braverman LE. Thyroid function and lipid subparticle sizes in patients with short term hypothyroidism and a population-based cohort. J ClinEndocrinolMetab 2008; 93: 888-894.

12. Teixeira P D E F, Reuters VS, Ferreira MM, et al. Lipid profile in different degrees of hypothyroidism and effects of levothyroxine replacement in mild thyroid failure. Transl Res 2008; 151: 224-231.

13. Lee WY, Suh JY, Rhee EJ, Park JS, Sung KC, Kim SW. Plasma CRP, apolipoprotein A-1, apolipoprotein B and Lp(a) levels according to thyroid function status. Arch Med Res 2004; 35: 540-545.

14. Canaris GJ, Manowitz NR, Mayor G, Ridgway EC. The Colorado Thyroid Disease Prevalence Study. Arch Intern Med 2000; 160:526-534.

15. Walsh JP, Bremner AP, Bulsara MK, O’Leary P, Leedman PJ, FeddemaP, MichelangeliV.Thyroid dysfunction and serum lipids: a community-based study. ClinEndocrinol (Oxf) 2005; 63:670-675.

16. Monzani F, Caraccio N, Koza kowa` M, Dardano A, Vittone F, VirdisA, Taddei S, Palombo C, Ferrannini E. Effect of levothyroxinereplacement on lipid profile and intima-media thickness in subclinicalhypothyroidism: a double-blind, placebo-controlled study. J ClinEndocrinolMetab 2004; 89:2099-2106.

17. Zhu $\mathrm{X}$ and Cheng SY. New insights into regulation of lipid metabolism by thyroid hormone. Current Opinion in Endocrinology, Diabetes and Obesity 2010; 17(5): 408- 413.

18. Laway BA, War FA, Shah S, Misgar RA, Kotwal SK. Alteration of lipid parameters in patients with subclinical hypothyroidism. Int J EndocrinolMetab 2014 ; 12(3): e17496.

19. Lai Y, Wang J, Jiang F, Wang B, Chen Y, Li M, Liu H, Li C, Xue H,Li N, Yu J, Shi L, Bai X, Hou X, Zhu L, Lu L, Wang S, Xing Q, Teng X, Teng W, Shan Z. The relationship between serum thyrotropinand components of metabolic syndrome. Endocr J 2011; 58:23-30.

20. Santi A, Duarte MMMF, Moresco R N , Menezes C, Bagatini M D , Schetinger M R , Loro V L . Association between thyroid hormones, lipids and oxidative stress biomarkers in overt hypothyroidism. ClinChem Lab Med 2010;48: 1635 1639.

21. Lakshmi LJ, Eli M, Doddigarla Z, Suchitra K. Serum Lipids and Oxidative Stress in Hypothyroidism. Journal of Advance Researches in Biological Sciences 2013; 5(1):63-66.

22. Bell RJ, Rivera-Woll L, Davison SL, Topliss DJ, Donath S, Davis SR. Well-being, health-related quality of life and cardiovasculardisease risk profile in women with subclinical thyroid disease-acommunity-based study. ClinEndocrinol (Oxf) 2007; 66:548-556. 
23. Asvold BO, Vatten LJ, Nilsen TI, Bjøro T. The associationbetween TSH within the reference range and serum lipid concentrations in a population-based study. The HUNT Study. Eur J Endocrinol2007; 156:181-186.

24. Hueston WJ, Pearson WS. Subclinical hypothyroidism and therisk of hypercholesterolemia. Ann Fam Med 2004; 2:351355 .

25. Shakoor S K A, Aldibbiat A, Ingoe L E. et al., Endothelialprogenitor cells in subclinical hypothyroidism: the effect of thyroid hormone replacement therapy Journal of ClinicalEndocrinology and Metabolism, 2010; 95(1):319-322.

26. Cachefo ANA, Boucher P, Vidon C, .Dusserre E, Diraison F, and Beylot M. Hepatic lipogenesis and cholesterol synthesis in hyperthyroid patients. Journal of Clinical Endocrinology and Metabolism 2001; 86 (11): 5353-5357.

27. Rizos CV, Elisaf MS, Liberopoulos EN. Effects of thyroid dysfunction on lipid profile. Open Cardiovasc Med J 2011; 5: 76-84.

28. Pearce EN. Update in lipid alterations in subclinical hypothyroidism. J ClinEndocrinolMetab 2012; 97(2):326-33

29. Santi A , Marta MM F , Duarte MMMF , deMenezes C C , Loro V L. Association of Lipids with Oxidative Stress Biomarkers in Subclinical Hypothyroidism. Int J Endocrinol $2012 ; 2012$ : 856359

30. Naazeri S, Rostamian M, Hedayati M. Impact of Thyroid Dysfunction on Antioxidant Capacity, Superoxide Dismutase and Catalase Activity. Zahedan J Res Med Sci 2014; 16 (1): 51-54.

31. Dave B N, Paradkar N M. Total superoxide dismutase, Cu/Zn superoxide dismutase and glutathione peroxidase in untreated hyperthyroidism and hypothyroidism. JK Science 2009;11: 6 - 10.

32. Carmeli E, Bachar A, Barchad S, Morad M , Merrick J. Antioxidant status in the serum of persons with intellectual disability and hypothyroidism: a pilot study. Res Development Disabil 2008; 29: 431 - 438.

33. Pasupathi P, Latha R. Free Radical Activity and Antioxidant Defense Mechanisms in Patients with Hypothyroidism. Thyroid Science2008; 3: CLS1-6.

34. Reddy VS , Gouroju S, Suchitra MM, Suresh V, Sachan A, Srinivasa Rao PVLN ,Bitla AR. Antioxidant Defense in Overt and Subclinical Hypothyroidism HormMetab Res 2013; 45:754-758.

35. Babu K, Jayaraaj IA, Prabhakar J. Effect of Abnormal thyroid hormone changes in lipid peroxidation and Antioxidant imbalance in Hypothyroid and Hyperthyroid patients. Int J Biol Med Res. 2011; 2(4): 1122 - 1126.

36. Nanda N, Bobby Z, Hamide A, Koner B C, Sridhar M G. Association between oxidative stress and coronary lipid risk factors in hypothyroid women is independent of body mass index. Metabolism 2007;56: 1350 - 1355.

37. Haribabu A, Seshadri Reddy V, Pallavi C, Aparna R. Bitla AR, Sachan A, Pullaiah P, Suresh V, Srinivasa Rao PVLN, Suchitra MM. Evaluation of protein oxidation and its association with lipid peroxidation and thyrotropin levels in overt and subclinical hypothyroidism. Endocrine 2013; 44:152-157.

38. Nanda N, Bobby Z, Hamide A. Oxidative stress and protein glycation in primary hypothyroidism. Male/female difference. ClinExp Med 2008;8: $101-108$.

39. Baskol G, Atmaca H, Tanriverdi F, Baskol M, Kocer1 D, Bayram F. Oxidative stress and enzymatic antioxidant status in patients with hypothyroidism before and after treatment. ExpClinEndocrinol Diabetes 2007; 115: 522 - 526.

40. Cheserek MJ, Wu GR, Ntazinda A, Shi YH, Shen LY, Le GW. Association between thyroid hormones, lipids and oxidative stress markers in subclinical hypothyroidism. J Med Biochem 2014;33: 1-9.

41. Coria MJ, Pastrán AI, and Gimenez MS. Serum oxidative stress parameters of women with hypothyroidism, ActaBiomedica 2009; $80: 135-139$.

42. Kebapcilar L, Akinci B , Bayraktar F, Comlekci A, Solak A, Demir T, Yener S, Küme T, Yesil S . Plasma thiobarbituric acid-reactive substance levels in subclinical hypothyroidism. Medical Principles and Practice $2007 ; 16: 432-436$.

43. Napoli C, Postiglione A, Triggiani M, Corso G, Palumbo G, Carbone V, et al. Oxidative structural modifications of low density lipoprotein in homozygous familial hypercholesterolemia. Atherosclerosis 1995; 118(2):259-73.

44. Venditti P, Meo SD. Thyroid hormone-induced oxidative stress. Cell Mol Life Sci 2006; 63(4): 414-34.

45. Fernandez V, Tapia G, Varela P, Romanque P, Cartier-Ugarte D, Videla LA. Thyroid hormone-induced oxidative stress in rodents and humans: A comparative view and relation to redox regulation of gene expression. Comp BiochemPhysiol $\mathrm{C}$ ToxicolPharmacol 2006 142: 231-9.

46. Wang D, Feng JF, Zeng P, Yang YH, Luo J and Yang YW. Total oxidant/antioxidant status in sera of patients with thyroid cancers. Endocrine-Related Cancer 2011; 18: 773-782. 